\title{
Unamuno, Crítico de la Literatura
}

\section{Hispanoamericana}

$T^{\text {NTRE los primeros escritos de Unamuno figura ya uno }}$ sobre la literatura hispanoamericana. El maestro empezó a escribir poco antes de 1890. Están aún por coleccionar los ensayos y los artículos con que por aquel entonces contribuyó a periódicos de Bilbao y de Madrid. (1) El primero de los reunidos en la edición de sus Ensayos es de 1894, el mismo año en que apareció en la Revista Española de Madrid el célebre ensayo sobre Martín Fierro con que el joven profesor salmantino inició sus trabajos como crítico de la literatura hispanoamericana. Tan espontáneo y tan penetrante salió el ensayo, que al autor se le concedió en seguida un puesto muy alto entre los pocos españoles que hasta aquel momento habían demostrado un interés sincero y comprensivo en la vida cultural de América.

Pero a pesar de la estima y de la fama que ganó por su honda apreciación del Martín Fierro, Unamuno no volvió a escribir otra crítica de libro americano hasta cinco años después, cuando en las páginas de La Ilustración Española y Americana apareció su estudio de otro libro gauchesco, Nastasio, de Francisco Soto y Calvo.

Pasaron otros dos años, sin embargo, antes de que Unamuno se dedicara a una crítica seria y continua. Cuando la redacción de $L a$ Lectura buscó a quien encargar de la sección hispanoamericana, no encontró a nadie mejor preparado que Unamuno para la tarea de comprender y apreciar la América 
literaria. Unamuno aceptó y en el primer número de La Lectura que salió a luz en enero de 1901, apareció su primer artículo titulado "De literatura hispanoamericana". Por seis años, con una regularidad sorprendente, Unamuno mantuvo al día a los lectores de la revista sobre el movimiento literario americano, ofreciéndoles una crítica nutrida y sólida de más de cincuenta libros contemporáneos de allende el mar. Confesó al principio que iba a dar más importancia a las letras argentinas por ser las que mejor conocía. $Y$ en efecto así fué, porque resulta que casi la mitad de las obras que criticó son argentinas.

Una ojeada rápida de los títulos y de los autores de estos libros revela que Unamuno leía una gran variedad de obras: poesía, historia, geografía, crónicas, crítica, viajes, novelas, ensayos, traducciones, estudios lingüísticos, y revela también que muchos de estos libros y autores han desafiado el transcurso del tiempo, habiendo entrado de lleno en los anales de la historia de la literatura hispanoamericana. Sería bien recordar aquí unos cuantos libros y autores de los que más le entusiasmaban a Unamuno. Además del Martín Fierro, habría que citar Idolos rotos y Sangre patricia, a cuyo autor, Díaz Rodríguez, no vaciló en llamar "el mejor de los novelistas sudamericanos" que hasta aquel entonces conocía; España contemporanea, de Dario, a quien - a pesar de que siempre estaban opuestos en cosas de arte- dijo que le debía gratitud porque el americano hasta cuando combatía sus puntos de vista, le trataba con la mayor consideración; Vivos, tilingos y locos lindos de Grandmontagne, "el libro moderno de más enjundia y más meollo" que había recibido de América, y "uno de los libros de mayor contenido y de más fuerza" que había leído, en español, en esos años; Prosa ligera, de Miguel Cané, "libro, ante todo, de buena voluntad, moderado, equilibrado siempre, sin llamativas de ninguna clase, algo como la conversación de un hombre de mundo que ha viajado, ha visto y ha oído mucho"; El éxodo y las flores del camino, de cuyo autor dijo: "Hace augurar que Nervo dará obras de gloria a su patria"... a juzgar por "todo lo que hay de delicado, de cordial, de íntimo y de hondamente humano en él"; Carácter de la literatura del Perú independiente, de José de la Riva 
Agüero, "tesis que debe hacernos esperar que su autor llegue a ocupar, con el tiempo, uno de los más eminentes puestos en la república de nuestras letras - una misma allende y aquende el Océano-; una tesis tan llena de sana y sólida doctrina, de juicio independiente-y sereno, que sorprende proceda de un estudiante que termina su carrera"; y Viajes por la República Argentina, de Manuel Bernárdez, que obtuvo del crítico la siguiente confesión: "Libros así nos indemnizan a los aficionados a cosas americanas de esos otros libros que no saben a tierra alguna, y en que en uña lengua que ni es castellano ni es idioma nacional de parte alguna se nos cuentan ñoñeces clásicas o modernistas traducidas de cualquier traducción".

Unos 24 son los libros que Unamuno acogió con amabilidad si no con entusiasmo. Por estar éstos entre los dos extremos, me permito el no citarlos. Además, con mencionar ahora los que apenas toleraba, quedarán apartados aquéllos en la bibliografía del final.

Una docena son los que, no obstante sus esfuerzos por decir todo lo bueno que podía, sólo le servían de blanco para poder señalar más enfáticamente lo débil y lo malo de las letras americanas. Entre éstos los que con menos disgusto había leído eran Las sombras de Hellas, de Leopoldo Díaz "Hellas" debiera ser "Hélada", según el profesor salmantino de lengua y literatura griegas, para no rimar con "ellas"; El castillo de Elsinor, de Pedro-Emilio Coll, libro en que es demasiado marcada.la influencia francesa; y $E l$ triunfo del ideal, de Pedro César Dominici, "Una novela de tesis... (que) ... suena... a falso y a frío". Los que más le disgustaron fueron: Los nuevos caminos, de Alberto Ghiraldo, cuya principal característica "se llama simplismo"; Nostalgia, de Francisco Soto y Calvo, que le parecía una equivocación... "novela realista en verso"; Un país nuevo, de Benjamín Vicuña Subercaseaux, libro que le hacía reír y burlarse del patriotero autor; y La ciudad de las ciudades del mismo autor, "excelente como tipo de una dolencia de que apenas si empiezan a curarse los americanos de lengua española", libro que no pudo soportar por el exceso de galomanía que lo caracteriza y que le arrancó este consejo para el joven chileno: "Alíviese, $2 \star$ 
pues, el Sr. Vicuña Subercaseaux, de su afrancesamiento, y. por patriotismo, pues tan ardiente patriota es, cuelgue su pluma y busque el servir a Chile de otra manera, y será uno de los mayores servicios que pueda rendir a su noble patria".

El último artículo que en su función de crítico escribió para La Lectura es el que apareció en los números correspondientes a septiembre y a octubre de 1906 bajo el título "Algunas consideraciones sobre la literatura hispano-americana", el cual se recogió más tarde para el tomo VII de sus Ensayos. En éste, Unamuno repitió, "ampliándolas y remachándolas, no pocas de las reflexiones" que venía dejando caer en sus notas sobre libros americanos.

De aquí en adelante las actividades de Unamuno como crítico de las letras americanas son más conocidas aunque mucho más reducidas y de menor significación. Su valiosísima colaboración en La Lectura le había puesto a la cabeza de los críticos peninsulares que por aquel entonces se preocupaban de literatura americana, $y$ era de esperarse, por ende, que los editores le pedirían "prólogos" para los libros americanos que publicaban. De éstos los más conocidos serán los que escribió para la edición de Poesías de Silva, para Alma América de Chocano, y para En voz baja, de Nervo. Pero aunque seguía interesándose en la literatura hispanoamericana y continuaba revelando sus opiniones y su apreciación de libros y de literatos americanos, interpolándolas de vez en cuando en sus obras posteriores, la época en que realmente se formulaba el criterio con que juzgaba las letras americanas se reduce al período anterior a 1907, más aún, a los seis años en que sirvió como crítico de La Lectura.

En los primeros apuntes que nos proporciona en el artículo sobre Martín Fierro, Unamuno nos revela ya una de las normas que le han de guiar en su apreciación y su estima de la literatura americana: la de que la literatura americana escrita en lengua española no pudiera menos de descubrir rasgos comunes con la peninsular, rasgos que se transparentan con más claridad precisamente en las obras más netamente regionales. Por eso llama ridícula la pretensión de los argentinos de considerar Martín Fierro obra de "una literatura privativamente argentina", obra que brota "de un espíritu 
nuevo que diferencia a los argentinos de los demás españoles", y por eso también afirma que de todo lo hispanoamericano que conoce es "lo más hondamente español. $\therefore$ poema de un Hernández, hijo de un Hernando español". . . "poema español hasta el tuétano" - afirmación que, claro está, no les cayó bien a los "argentinistas". Huelga decir que para Unamuno toda la literatura gauchesca forma parte más bien de la gran literatura hispánica que de una literatura exclusivamente argentina.

Este espíritu español lo. buscará Unamuno en toda obra que lea $y$ en casi todas lo encuentra en una forma $\mathbf{u}$ otra. Lo ve en esas páginas de Viajes por la República Argentina de Bernárdez èn que "se lamenta de la sed de las tierras y de lo mucho que necesitan de agua", páginas que le parecen escritas en España y para España, sólo que -interpone el salmantino- "la que llamamos aquí política hidráulica va en la Argentina más en serio que en España". (2) La literatura antioqueña, que dice muy simpática, "sí que es parte de nuestra literatura y nos suena a cosa nuestra y muy nuestra". Y Colombia toda le parece "un país nuestro... hasta en el carácter de sus luchas civiles... con la diferencia de que... en Colombia, los liberalés son los insurgentes y los del Gobierno son los carlistas". (3) ¡Qué no dirían los compatriotas de aquel "vigoroso y genialísimo Sarmiento" -a quien le quitó el igualmente vigoroso Unamuno toda la furia de su hispanofobia al afirmar que sólo exteriormente era antiespañol-al leer: "La verdad es que la historia argentina -cuanto más la conozco más me corroboro en ello- es uno de los capítulos más profundamente españoles de la historia del pueblo de lengua castellana."! En apoyo de su aserción puntualiza Unamuno estos rasgos de la historia argentina: "el tan característico cantonalismo incrustado en el alma española... la falta de espíritu público... el echar la culpa de todo al otro... y lo de que la revolución de la independencia pretendió pasar de un salto 'del estrecho régimen virreinal, a sistemas antagónicos de democracia pura, sin adaptaciones ni evoluciones previas'." (4) Y conforme a su conocida teoría de que "cada región, cada casta de las que componen a España debe procurar acusar, corroborar y fijar su propia 
personalidad..." para no perderla en el espíritu común sino más bien para poder contribuir así al enriquecimiento de ese mismo espíritu colectivo - "para que cada cual dé mejor su fruto y puedan tomar de él los demás lo que les convenga", (5) Unamuno no ve nada incompatible en que una obra como $\mathrm{Al}$ ma América sea a la vez "muy americana sin duda, pero no menos española". (6) Santiago Pérez-Triana es "colombiano de la más pura cepa española". (7) En Nuestra América se revela Bunge como "un escritor honda y radicalmente español..." (8) La literatura peruana de después de la Independencia es "literatura castellana provincial, ni más ni menos que la de las islas Canarias, o de Aragón o Murcia, por ejemplo, puesto que nada tiene que ver con la literatura la dependencia o independencia política de la región donde se cultiva". (9) El negar esto sería el "aplicar a cosas del espíritu un criterio meramente topográfico. Aquello es una continuación de la España del siglo XVI tanto como esto, y en ciertas regiones americanas, en parte de Colombia, verbigracia, aún más fielmente que esto". (10) Que no es lo mismo decir, desde luego, que la región de donde la lengua procede da, o debe pretender dar, el tono ni a la lengua ni a la literatura.

Unamuno nos descubre ya desde el principio lo que para él sirve de nexo más fuerte entre España y América, lo que más aviva el españolismo americano: "...me parece que más que con la sangre les va a los sudamericanos el españolismo con la lengua...", (11) y característicamente -en su capacidad de profesor del idioma español y de escudriñador de lo eterno del espíritu hispánico- casi siempre trata, juntamente del idioma y del espíritu, identificándolos. Así es que su primera contribución a La Lectura se abre con esta afirmación: "Como la lengua es la sangre del espíritu del pueblo, y base de toda disposición orgánica la sangre, hay entre nuestra literatura y la de las naciones americanas de lengua castellana una hondísima comunidad mucho más honda de la que por allá se sospecha y cree". (12) $\mathrm{Y}$ en su "Prólogo" a Alma América vuelve a afirmar: "Sí, la lengua, que es la sangre del espíritu, es el fundamento de la Patria espiritual; y, más dueños de América nos hace Cervantes que hizo a nuestros abuelos Colón". 
Era de esperarse, pues, que al escarnecerles a los argentinos por su ridicula pretensión de considerar Martín Fierro obra de una literatura "privativamente argentina", a la vez se mofaría de ellos por calificar "pomposa y disparatadamente de idioma nacional (argentino, se entiende) el castellano popular y neto en que está escrito Martín Fierro, repleto de términos que por designar objetos del nuevo mundo tienen nombre aquí desconocido, de modismos, fonetismos y formas dialectales tan poco indígenas de la Pampa, que aún se usan en no pocos lugares de España. $Y$ cuando los vocablos del Martín Fierro no son españoles, son indios, pero no argentinos. iCuándo les entrará a esos americanísimos lo que les dijo su compatriota Calixto Oyuela, que la historia nos enseña que de los idiomas formados y fijados sólo pueden salir jergas informes'." (13) Y que más tarde atacaría también al catalán que se figuraba había de nacer un nuevo idioma distinto del castellano - ya que no pudiera "catalanizarse a los hispanoamericanos..." (14) Jamás se cansa de repetir que el español de América y el de España "no se diferencia tanto en el fondo popular, hablado y vivo, cuanto en la espuma literaria escrita y en cierto modo muerta". (15) No puede aguantar la manía de los poetas americanos de plagar su poesía, sin venir a cuento, "de biguás, caicobés, cipós, ceibós, curupés, chajás, umburucuyás, mamangás, ñandús, y otros avechuchos, animalejos y yerbajos por el sólo empeño infantil de hacérnoslos más extraños a los españoles!" (16) Pero aún y con todo prefiere este cargamento de terminachos americanos a los galicismos de que harto abusan tantos neogongoristas, culteranos, coloristas, decadentistas, parnasianos, víctorhuguistas y otras especies de estufa que se le cuelan de allende el mar. Atento siempre a las peculiaridades lingüísticas introducidas a sabiendas o sin saberlo en los libros americanos, Unamuno no puede menos de señalarlas -y repetidas veces-a la atención del lector, como, por ejemplo, lo hace cada vez que tropieza con la ortografía nacional de "México". No puede empezar su artículo sobre Nervo sin primero manifestar, en descargo de escrúpulos de su conciencia, la repugnancia con que escribió "México" con " $x$ " en vez de "Méjico" con " $j$ ", "que es como racionalmente debe escribirse, 
pues esa ' $x$ ' es de lo más absurdo $y$ más anacrónico que conozco, y más que pueriles, las razones que se dan por su empleo". (17) Un año después, para no ultrajar más su conciencia ya tan maltratada por la avalancha de " $x$ " que le llega de la Nueva España, se niega a escribirlo con " $x$ " porque le parece acto de cobardía de parte de la raza el acomodar la ortografía de "México" a la de "Texas" para no ofender a los gringos. (18) $\mathrm{Y}$ tanto le confunden a Unamuno como a nosotros las dos enes con el apellido del inescrupuloso general "mejicano", "Santa Anna". (19) Menos severo con el rioplatense Bernárdez, "cuyo castellano corriente y excelente (está) limpia y correctamente construído de ordinario, pero con cierto dejo criollo que le da gracia y originalidad propias", se burla de él por el uso del verbo "ubicar", "que huele a cosa técnica en frases como 'ubica el joven ex ministro todo el ímpetu de sus optimismos...' donde diría el español lisa y llanamente pone", añadiendo "como no sea que el Sr. Bernárdez rehuye el verbo 'poner', como rehuye, cual buen criollo argentino, el verbo 'coger', tan corriente, tan inocente y $\tan$ usual en España". (20)

Unamuno está de acuerdo con Miguel Cané en que "la pobreza de la autoridad de la Academia Española y el 'mandarinismo' estrecho de sus preceptos, fueron y han sido parte no exigua a mantener vivo el espíritu de oposición en las comarcas americanas", y de acuerdo también con lo que decía Juan María Gutiérrez al pedir "la lengua española, una e indivisible, bien común de todos los que la hablan y no petrificada e inmóvil, patrimonio exclusivo no ya de una nación, sino de una autoridad". (21)

Concurrentemente con estas cuestiones de españolismo y del idioma español en América, se plantea la del americanismo. ¿Cuáles serán las ideas de Unamuno sobre este tan asendereado tema? Respecto a las diversas clases de americanismo señaladas por Riva Agüero: el histórico, el regional y el descriptivo, observa satíricamente que "el histórico, cuando busca asuntos en la época precolombina, fracasa, porque los americanos son poco menos extraños que nosotros a las civilizaciones quechua, azteca o guaraní". (22)

Para Unamuno el americanismo más legítimo es el des- 
criptivo, y el problema todo se resuelve sólo con tal que los americanos se americanicen: que dejen de descubrirles Europa a los europeos y que se dediquen a descubrir para sí todo el mundo nuevo que les invita inspiración. Existe una hondísima comunidad entre la literatura española y la de América, eso sí, pero existe también "no poco de diferencial, debido a lo que el cambio de clima y de íntimas condiciones de vida y la mezcla de diversas sangres materiales modifica..." (23) En hacer resaltar esta diferencia lograrán la originalidad literaria y no en ver y en juzgar a sus respectivos países a través de libros europeos. Por eso Unamuno se entusiasmó tanto por Martín Fierro: lo que muchos críticos no comprenden es que para Unamuno el poema "apenas tiene sentido alguno desglosado de nuestra literatura" pero no quita en nada el que sea a la vez gran obra argentina o americana. Ya hemos visto que Alma América le parece "muy americana sin duda, pero no menos española", e Idolos rotos le parece una novela "venezolana, americana" no obstante que muchos elementos de la obra son "de innegable filiación europea". Fuera de esto no nos queda sino un ejemplo más con que nos aclara un tanto su concepto del americanismo. En su crítica de España contemporánea dice que Darío piensa "en genuino americano", añadiendo que "hay algo de inarticulado, de desgranado, de discreto (en el sentido etimológico de este vocablo, el que a concreto se opone), de invertebrado en el decir y exponer de Darío; más que línea seguida, sigue línea punteada... es cinematográfico, hasta en el titilar de las imágenes que se suceden... y así es su pensamiento". (24)

Bien poco y nada muy concreto, como se ve, es lo que de americanismo nos dice Unamuno. Creo, sin embargo, que su actitud toda para con el españolismo y el americanismo está admirablemente expresada en aquel consejo tan franco y tan escueto que dió a los chilenos: "No, el roto chileno, ni es latino, ni tampoco araucano-gótico... El chileno es chileno y debe bastarle, y su lengua es lengua española". (25) $Y$ creo además que si le hubieran pedido una definición del americanismo habría contestado de la misma manera en que respondió a la pregunta: “QQué es la hispanidad?”, y, conociéndole, no tendríamos derecho a esperar otra respuesta. Si el 
que tanto deseaba saber lo que era la hispanidad, confesaba que no lo sabía, que aprendan de su respuesta una valiosísima lección los que se afanan por saber el sentido y el significado del americanismo: "¿Qué es la hispanidad? Ah, si yo lo supiera... Aunque no, mejor es que no lo sepa, sino que la anhele, y la añore, y la busque, y la presienta, porque es el-modo de hacerla en mí". (26)

En vista de que sus actividades como crítico de la literatura hispanoamericana coincidieron con la invasión de tanto libro americano plagado de "arlequinados pendejos y de gongorinas lentejuelas" de origen parisiense-bulevardero, milagro hubiera sido si el reconocido misogalismo o francofobia de Unamuno - de la cual no sentía deseo alguno de curarseno hubiera rebosado tras la lectura de tanto fárrago galicista. El autor que atrajo sobre sí el ataque más fulminante de cuantos dirigía Unamuno contra los sudamericanos afligidos de galomanía fué el chileno que se mostraba más Subercaseaux que Vicuña por haber llamado a París "la ciudad de las ciudades", epíteto que le sirvió de título para todo un libro en que nos viene "repitiendo las mil y una vaciedades que acerca de su superioridad estamos oyendo hace un siglo". (27) ¿Por qué tan acentuada allá en América la influencia francesa? La respuesta de Pedro-Emilio Coll le pareció bien a Unamuno, quien aceptó, en parte por lo menos, la teoría "de que se encuentran analogías entre los efectos del calor sobre el individuo y los que determina una civilización avanzada: la sensibilidad nerviosa, la hiperestesia psíquica...", y, añadió el vasco, "Ia preocupación erótica". (28) Las letras francesas son "lógicas y sensuales"- - "dos cualidades que antes me repelen que me atraen"-y por eso les requieren "menos esfuerzo de comprensión" a los americanos "atacados como nosotros de ideofobia": "es... muy natural la fascinación que la literatura francesa ejerce sobre sociedades en formación cultural, pues ofrece papilla espiritual para espíritus tiernos. No exige mucha masticación ni digestión laboriosa. Es clara, transparente, accesible; demasiado clara, demasiado transparente, demasiado accesible. Buena, muy buena maestra de 
cultura es Francia; pero no olvidemos nunca aquel tan exacto verso de un soneto del gran crítico y poeta Mathew Arnold:

France, famed in all great arts, in none supreme (20)

Lo que más le fastidia a Unamuno es que la mayoría de los americanos imitan casi exclusivamente a los franceses - sin buscar en otras literaturas otras insinuaciones- $y, 10$ que es peor, casi siempre imitan a los poseurs bulevarderos: a De Groux, a Jean Moreas Papadiamantópulos - "fatuo, insoportable e hinchado"-, al mixtificador Remy de Gourmont, pontifice de los mercuriales, en vez de inspirarse en los valores sólidos de la cultura francesa. Grave error también lo de que los americanos creen que es "la literatura francesa la que mejor refleja y reproduce el espíritu clásico de la antigüedad, prejuicio naturalísimo en quienes no conozcan esta antigüedad sino a través de traducciones e imitaciones francesas y tampoco conozcan cómo otros pueblos cultos la han traducido e imitado". (30) Y lo que imitan es el muy falso helenismo del parisiense bulevardero "con todos esos enredos pseudo-clásicos y todos esos embrollos que les meten en la cabeza en ese cacho de París". (31) Revélase naturalmente en todo esto su menosprecio de los modernistas a quienes condena por buscar la reforma del verso castellano, o su modernización, por vías francesas... como si fuesen lo mismo ambos idiomas...: "si (la lengua española) ha de cumplir sus fines en los vastos territorios por que hoy se extiende... no es lo mejor moldearla a la francesa, ya que no deja de ser un disparate, eso de que la lógica universal sea la lógica francesa". (32)

Alrededor de,estos puntos; que son-los que más. le sirven de norma: españolismo, lengua, americanismo y galomanía, gira gran parte de la crítica de Unamuno. Los demás no suelen repetirse tanto. Cosa que le preocupa casi por igual, sin embargo, es la cuestión religiosa. Echa muy de menos la preocupación religiosa en América, y a la falta de ella achaca, en parte a lo menos, que "los hispano-americanos no tienen ni han tenido ideal propio, y probablemente no lo tendrán en mucho tiempo". (33) Por la-misma razón teme que, mien- 
tras florece allá —en donde parece a ratos que va a soplar un nuevo soplo de paganismo sobre la tierra-la poesía que hable a la voluptuosidad de vivir, se ahogue esa otra poesía, íntima, recogida - la poesía religiosa. (34) Por eso también los americanos corren el riesgo gravísimo, tanto como los españoles, del mamonismo: la prosperidad material, sin contrapeso. (35) Y por eso llama "triste honor" el de la literatura chilena "por haber desterrado del laberinto histórico... . la conciencia que lucha entre el saber y la fe'," añadiendo, con motivo de la afirmación de Vicuña Subercaseaux de que " 'Santiago de Chile es una ciudad eminentemente intelectual," que "la intelectualidad no basta para la cultura, ni menos para la dicha". (36) Cree que la manía anticristiana, tan acentuada en muchos libros americanos, como, por ejemplo, en El triunfo del ideal de Dominici, "tiene por base un acentuado desconocimiento de la esencia e íntimo espíritu del cristianismo", (37) y cita esta manía como prueba de que todavía por allí "toman en serio la religión comtiana".

Le inquieta grandemente esta falta de preocupación religiosa; pero el exceso de patriotismo americano sirve para volverle a alentar. Una de las cosas por las cuales Chile le era tan simpático - y lo era para él muy de veras a pesar de lo mucho que se burlaba de los chilenos- es el patriotismo de sus escritores y la manera tan ingenua que ellos tienen de ensalzar a su patria, dejándose "llevar a deprimir las de los demás pueblos sudamericanos". (38) Le deleita en especial mofarse del pobre y muy burlado Vicuña Subercaseaux por su desenfrenada patriotería, que no le reprocha sin embargo, por considerarla como obra moral para los chilenos "mejor que lo nuestro, cual es lo de rebajarnos y hasta calumniarnos a todas horas". Como buen vasco - para quien los vascongados son los mejores hombres de España- Unamuno aplaude la intensa confianza del chileno en afirmar que los chilenos son los mejores hombres de Sudamérica: "Lo bueno, de dentro; lo malo, de fuera. En Chile se debe todo a los chilenos, como en mi Vizcaya se debe todo a los vizcaínos". (39) Tampoco puede menos de aplaudir al hispanoamericano el "delicioso" trabajo de Nervo que en París sale del paso en mil ocasiones con un chez nous que le obliga al francés, épaté, 
a repetir con cierta condescencia: "Qu'est-ce $q u$ 'on va faire... chez lui c'est comme ca." La tan arraigada galofobia de Unamuno le reclama esta aprobación regocijada: "Tiene razón el hispanoamericano, amigo Nervo, y hace bien en esgrimir su chez nous, y en enseñar a los animales condecorados que no saben geografía, que hay otros paises, y otras costumbres y otros modos de pensar y vivir que no los suyos... Que si Méjico es un 'accidente geográfico', un accidente geográfico es tambièn París; y en cuanto a las puestas de sol del Brasil, no sé en qué o por qué hayan de ser menos hermosas que esas puestas de nuances, de los tan sobados nuances, y del rosa muerto, el fresa fané, el azul tenue y el malva discreto". (40).

El artículo sobre Riva Aguiero le proporcionó a Unamuno la oportunidad de secundar ciertas conclusiones del peruano sobre el carácter de la literatura de su patria, a saber: la literatura del Perú es incipiente y predominantemente imitativa, y en ella escasean las obras definitivas, conclusiones que el salmantino encontró aplicables en general a toda la literatura americana. De otros estudios sacamos estos defectos - los últimos que aquí puntualizamos-a que llama atención en su análisis de las letras americanas: las obras históricas y científicas suelen ser "declamaciones políticas"; los literatos americanos sufren del mismo vicio de los españoles: la vanidad literaria aún más poderosa allá - "si es que esto es posible" - que en España; y, añade, sufren de otro vicio también, que es el esnobismo, vicio igual o peor que el de España que es la ramplonería.

Pero no debemos creer que sólo encontraba defectos y vicios en la América literaria; (41) los que señalaba se los reprochaba por considerar a los hispanoamericanos miembros de la gran familia hispánica y por haber intentado arrancar estos mismos defectos de su propia patria literaria. Veía mucho en América que le gustaba profundamente, y la mayoría de los autores que apreciaba:-Sarmiento, Zorrilla de San Martín, Rodó, Darío, Díaz Rodríguez, Silva, Palma, Martí, González-Prada, figuraban, y seguirán figurando, entre los más ilustres literatos americanos. Jamás pasó a América; la conoció sólo mediante la lectura de libros americanos; (42) pe- 
ro tan penetrantes y tan agudas eran sus facuitades críticas y tan apasionados sus anhelos de conocer esta América española, que para él seguía siendo prolongación espiritual de su querida España, que no había nadie en Europa, en aquella época por lo menos, que la comprendiera y la interpretara tan bien como él.

Por la sinceridad y la franqueza con que les decía a los americanos lo que les dolía, tenía que soportar a veces ataques muy injustos de los que más padecían del esnobismo y de la vanidad literaria. Fué esta, sin duda, la razón de por qué América perdió tan temprano los servicios de su más esclarecido intérprete y amigo. En mayo de 1903 Unamuno salió a su propia defensa, revelando entonces que más de una vez le había pesado el haberse metido a crítico de literatura americana. Confesó que era profesión dañosa para el que la ejerce y que él no servía para crítico por carecer de "cierta imperturbabilidad y hasta dureza de corazón", si había de ser sincero siempre. Pero hay que repetir sus propias palabras: "Y esto es lo más terrible del oficio de critico, lo verdaderamente terrible de él: el tener que engullirse tanto fárrago, perdiendo un tiempo precioso... Y esto se agrava cuando de jóvenes literatos americanos se trata. Conservo una carta de un joven escritor venezolano en que me declara que he perdido a sus ojos y he caído del pedestal en que me tenía puesto, por una leve indicación que hice respecto a un libro suyo, dejando entrever que el tal libro me pareció, y sigue pareciéndome, una obra mediana y sin valor. Entonces descubrió en mí al español, al español rudo y beocio, sin chispa de espíritu ático, que está oculto bajo apariencias de europeo moderno". (43)

Unos años después Unamuno entregó a Ugarte su pluma de crítico para no volver a meterse sino contadas veces a publicar opiniones e impresiones de la literatura americana. Pero antes de ceder su puesto habló lisa y llanamente a sus compatriotas, señalándoles el rumbo que debían tomar en el futuro respecto a sus relaciones con la América hispana, consejo que tan digna $\mathrm{y}$ tan concienzudamente ponen en práctica hoy los que como sus discípulos reanudan la labor del maestro salmantino. 
“...me parecen dañosísimos y disparatados los pujos de magisterio literario respecto a América, que aquí en España se dan muchos, el desatinado propósito de ejercer el monopolio del casticismo, y establecer aquí la metrópoli de la cultura... La necia y torpe política metropolitana nos hizo perder las colonias, y una no menos necia ni menos torpe conducta en cuestión de lengua y de literatura podría hacernos perder - si estas cosas se rigieran por procedimientos de escritores y literatos-la hermandad espiritual. Tenemos que acabar de perder los españoles todo lo que se encierra en eso de madre patria, y comprender que para salvar la cultura hispánica nos es preciso entrar a trabajarle de par con los pueblos americanos y recibiendo de ellos, no sólo dándoles": (44)

(1).-Véase: Angel del Río, "Miguel de Unamuno", Revista Hispánica Moderna, 1, 1, octubre de 1934, p. 14.

(2).-La Lectura, V, 49, enero de 1905, pp. 70-73.

(3).-Estas reflexiones salieron de su lectura de Inocencio de Rendón y Emociones de la guerra de Max Grillo. Véase La Lectura, VI, 61, enero de 1906, pp. 84-93.

(4).--(Lucas Ayarragaray, La anarquía argentina y el caudillismo), La Lectura, V, so, febrero de 1905, pp. 190-194.

(5).-El porvenir de España, p. 124.

(6).-- "Prólogo", Alma América, p. XI.

(7).-(Reminiscencias tadescas), La Lectura, III, 30, junio de 1903, pp. 240-242.

(8).-La Lectura, III, 32, agosto de 1903, pp. 532-538.

(9).-Citado de Riva Agüero. Véase Ensayos, VII, p. 123.

(10).-Ensayos, VII, p. 136.

(11).-La Lectura, III, 32, agosto de 1903, pp. 532-538.

(12).-La Lectura, I, 1, enero de 1901, pp. 58-63.

(13).-Loc. cit.

(14).- - De literatura hispanoamericana", loc. cit.

(15).--(Soto y Calvo, Nostalgia), La Lectura, II, 16, abril de 1902, pp. 646-651.

(16).- "El Gaucho Martín Fierro", loc. cit.

(17) - -La Lectura, III, 33, septiembre de 1903, pp. 96-101.

(18).-Véase La Lectura, IV, 41, mayo de 1904, pp. 98-105.

(19).-Ibid.

(20). - La Lectura, V, 49, enero de 1905, pp. 70-73.

(21).-Véase La Lectura, III, 34, octubre de 1903, pp. 237-240.

(22).-Ensayos, VII, pp. 136-137. ¡Cuán típica la razón que nos 
da del éxito de Tabaré y de la belleza y valor del poema: "De las obras inspiradas en el amor a esos antiguos pueblos indígenas sólo conozco una de veras hermosa, el más sentido y más hermoso poema americano que conozco, y es el magnífico Tabaré, del grande, del grandísimo poeta uruguayo Zorrilla de San Martín. $Y$ es porque en ese poema se canta precisamente la extinción del pueblo chảrrúa, su forzosa desaparición ante la raza española"!

(23).- "De literatura hispanoamericana", loc. cit.

(24). - La Lectura, I, 7, julio de 1901, pp. 116-119.

(25).-La Lectura, VI, 62, febrero de 1906, pp. 207-220.

(26).-Véase Alonso, Antologia de ensayistas españoles, New York, Heath \& Co., 1936, pp. 70-71, citado de Sintesiș, Buenos Aires.

(27).,La Lectura, VI, 62, febrero de 1906, pp. 207-220.

(28).-Véase ("Notas sobre la evolución literaria en Venezuela"), La Lectura, I, 6, junio de 1901, pp. 63-72.

(29).-La Lectura, VI, 62, febrero de 1906, pp. 207-220.

(30). -Ibid.

(31).-La Lectura, III, 36, diciembre de 1903, pp. 535-537.

(32).-La Lectura, III, 33, septiembre de 1903, pp. 96-101.

(33). - Citado de Riva Agüero, Ensayos, VII, p. 139.

(34).-Véase el "Prólogo" de Alma América, p. XIII.

(35).-Véase Ensayos, VII, p. 140.

(36.).-La Lectzira, IV, 42, junio de 1904, pp. 224-232.

(37).-La Lectura, I, 7, junio de 1901, pp. 116-119.

(38).-La Lectura, VI, 62, febrero de 1906, pp. 207-220.

(39).-La Lectura, IV, 42, junio de 1904, pp. 224-232.

(40).-La Lectura, III, 33, septiembre de 1903, pp. 96-101.

(41). -No viene al caso ni atacar ni hacer apología de las ideas que sobre América expresó. Basta sẹnalar que los hispanoamericanos mismos antes que nadie se dieron cuenta de la profunda verdad de su crítica, o por lo menos comprendieron los motivos que a veces le llevaron a la exageración. Veamos, por ejemplo, lo que dice Luis Echavarri en su artículo "Unamuno y América" en que estudia en términos generales la actitud del salmantino para con la América hispana: "Otra cosa se precisa tener en cuenta. La época en que Unamuno escribió sus estudios referentes a América está ya algo lejana. Una veintena de años, en los tiempos modernos, cambia mucho las cosas. Debemos confesar, por lo tanto, que aunque algunas de las modalidades espirituales atribuídas por Unamuno a los países de América ya han desaparecido o se han transformado mucho, lo esencial subsiste todavia, pues los pueblos no suelen cambiar de alma de un día para otro". (Cultura Venezolana, XIII, 101, febrero a marzo de 1930, p. 242).

(42).-Su padre sí conoció personalmente a América, a donde fué como joven con sus tres hermanos. Pasó unos años en "la región del $\mathrm{Pa}$ cífico" de México donde recogio una biblioteca de unas quinientas obras "útiles". Con estas obras - "y acaso por eso menos plata"- volvió a su 
tierra. Fué en esta biblioteca familiar de su padre donde Unamuno aprendió a interesarse por las cosas de la América Española. Dejémosle hablar al hijo mismo respecto al significado de lo que arriba queda dicho: "... como se dice tanto... de lo que los 'indianos' o 'americanos" han contribuído a la formación de la conciencia pública en esas regiones (cantábricas) a la mejor educación de sus hijos, y a la liberalización del espíritu social... Si mi padre se hubiera quedado en su pueblo nativo, es más que seguro que the habria faltado lo más. de la base sobre que se formó mi conciencia civil, mi espíritu público... Por mi' parte, no espero la difusión de ese ni de ningún otro producto espiritual y artístico de la América Española, de eso que se llama ahora intercambio intelectual, y más si ha de ser universitario; sólo la espero de que algún americano los traiga acá como mi padre trajo antaño algunos libros... y que parte de una futura generación española se instruya en el conocimiento de las cosas de allá". Véase "La biblioteca de mi padre", Volantes de El Libro y el Pueblo, I, 2, abril de 1932, pp. 12-14.

(43).- "Entremés justificativo", La Lectura, III, 29, mayo de 1903, pp. $95-98$.

(44),-Ensayos, VII, pp. 134-135.

\section{BIBLIOGRAFIA DE UNAMUNO SOBRE LITERATURA IBEROAMERICANA}

"El Gaucho Martín Fierro", Revista Española, I, 1, 5 de marzo de 1894, pp. 5-22 (firmado en Salamanca, febrero de 1894).

"La literatura gauchesca" (Sobre Nastasio de Francisco Soto y Calvo), La Ilustración Española y Americana, XLIII, 27, 22 de julio de 1899, pp. 44-46.

"Carta-Prólogo" a Francisco Soto y Calvo, El genio de la raza, Chartres, Imprenta de Durand, 1900, pp. Ix-xm.

"De literatura hispano-americana", La Lectura, I, 1, enero de 1901, pp. 58-63.

"Idolos rotos, por Manuel Díaz Rodríguez; 'Notas sobre la evolución literaria en Venezuela", por Pedro-Emilio Coll", La Lectura, I, 6, junio de 1901, pp. 63-72.

"El triunfo del ideal, por Pedro César Dominici; España Contemporánea, por Rubén Dario", La Lectura, I, 7, "julio de 1901, pp. 116119.

"La ciudad indiana, por Juan Agustín Garcia", La Lectura, I, 8, agosto de 1901, pp. 285-294.

"El fin de Satán y otros poemas, por José Santos Chocano; Notas $e$ impresiones, por Miguel Cané; Prosa rural, por Martín Gil", La Lectura, I, 12, diciembre de 1901, pp. 913-918. 
"Vivos, tilingos y locos lindos, por Francisco Grandmontagne", La Lectura, II, 13, enero de 1902, pp. 125-129.

"Los nuevos caminos, por Alberto Ghiraldo", La Lectura, II, 15, marzo de 1902, pp. 491-493.

"Nostalgia, por Francisco Soto y Calvo", La Lectura, II, 16, abril de 1902, pp. 646-651.

"El castillo de Elsinor, por Pedro-Emilio Coll", La Lectura, II, 18; junio de 1902, pp. 248-251.

"Primavera sentimental, por Fabio Fiallo; El alma encantadora de Paris, por Enrique Gómez Carrillo; Ensayos de critica e bistoria y otros escritos, por Alberto Nin y Frías", La Lectura, II, 23, noviembre de 1902, pp. 351-359; ibid., como "Prólogo" a Alberto Nin y Frías, Nuevos ensayos de crítica, Montevideo, s. f., pp. XVI-257.

"Sangre patricia, por Manuel Díaz Rodríguez", La Lectura, III, 28, abril de 1903, pp. 612-616.

"Prólogo" a Manuel Ugarte, Paisajes parisienses, París, Garnier Hnos., 1903, pp. XVI-248.

"Entremés justificativo", La Lectura, III, 29, mayo de 1903, pp. 95-98.

"Reminiscencias tudescas, por Santiago Pérez-Triana", La Lectura, III, 30, junio de 1903, pp. 240-242.

"Nuestra América, por Carlos Octavio Bunge", La Lectura, III, 32, agosto de 1903, pp. 532-538.

"El éxodo y las flores del camino, por Nervo", La Lectura, III, 33, septiembre de 1903, pp. 96-101.

"Prosa ligera, por Miguel Cané", La Lectura, III, 34, octubre de 1903, pp. 237-240.

"Las sombras de Hellas, pot Leopoldo Díaz", La Lectura, III, 36, diciembre de 1903 , pp. 535-537.

"Dos mil setecientas voces que bacen falta en el diccionario, por Ricardo Palma", La Lectura, III, 36, diciembre de 1903, pp. 537-539.

"Mi año literario, por Arturo Reynal O'Connor", La Lectura, IV, 38, febrero de 1904, pp. 221-222.

"La victoria del hombre, por Ricardo Rojas", La Lectura, IV, 39, marzo de 1904, pp. 364-366.

"Vida nueva, por E. Rodríguez Mendoza", La Lectura, IV, 40, abril de 1904, pp. 516-517.

"Las grandes mentiras de nuestra bistoria, por Francisco Bulnes", La Lectura, IV, 41, mayo de 1904, pp. 98-105.

"Un país nutevo (Cartas sobre Cbile), por B. Vicuña Subercaseaux", La Lectura, IV, 42, junio de 1904, pp. 224-232.

"Prólogo" a Clemente Palma, Cuentos malévolos, Barcelona, Salvat, 1904, pp. XVI-169.

"Los poetas del siglo VI de Roma, por José Tarnassi; y critica de las traducciones de Esquilo por Juan R. Salas E. y de Virgilio por Joaquín $\mathrm{D}$. Casasús, $\mathrm{y}$ de tres conferencias sobre literatura griega por Jesús Urueta", La Lectura, IV, 48, diciembre de 1904, pp. 453-456. 
"Viajes por la Repuiblica Argentina, por Manuel Bernárdez", La Lectura, $\mathrm{V}, 49$, enero de 1905 , pp. $70-73$.

"La anarquia argentina y el caudillismo, por Lucas Ayarragaray", La Lectura, V, 50, febrero de 1905, pp. 190-194.

"De litteris, por F. García Calderón", La Lectura, V, 54, junio de 1905, pp. 197-198.

"De literatura colombiana", La Lectura, VI, 61, enero de 1906, pp. 84-93.

"La ciudad de las ciudades, por B. Vicuña Subercaseaux", La Lectura, VI, 62, febrero de 1906, pp. 207-220.

"Geografia argentina, por Carlos M. Urien", La Lectura, VI, 63, marzo de 1906, pp. 332-336.

"Algunas consideraciones sobre la literatura hispano-americana", La Lectura, VI, 69, septiembre de 1906, pp. 1-15, 113-126; véase también Ensayos, VII, Madrid, Publicaciones de la Residencia de Estudiantes, 1918, pp. 99-156.

"Prólogo" a José Santos Chocano, Alma América. Poemas indo-españoles, Madrid, Librería General de Victoriano Suárez, 1906, pp. XXII346. "Prólogo" pp. XI-XIX.

"Prólogo" a José A. Silva, Poesías, Barcelona, [Imp. de P. Ortega], 1908, XIV-159 pp.; véase también Poesías, París-Buenos Aires, L. Michaud, [1913?], 251 pp. (Ed. definitiva-Colección de Autores HispanoAmericanos). "Prólogo", pp. 7-27; Poesías, Nueva edición, Barcelona, Maucci, s. f., pp. 190. "Prólogo", pp. 5-17; (1) véase también Poesías, Nueva edición, corregida, Barcelona, Maucci, [1918?], 239 pp., "Prólogo", pp. 5-22.

"Estudio preliminar: Don Quijote Bolívar", pp. I-XVI, a Simón Bolivar, Libertador de la América del Sur, Madrid, Buenos Aires, Renacimiento, 1914, 542 pp. Unamuno, editor.

" 'La voz baja', de Amado Nervo", prólogo a En voz baja, Madrid, Imp. de Juan Pueyo, 1920. (Biblioteca Nueva, Obras completas, tomo VII). "Prólogo", pp. 9-23.

"Sobre el estilo de Martí", Germinal, 1921, II, 3-4.

- "Hommage à Juan Montalvo", (Discurso), Revale de L'Amérique Latine, $\mathrm{X}, 2$, agosto de 1925, pp. 106-107.

"La biblioteca de mi padre", Volantes de El Libro y el Pueblo, I, 2, abril de 1932, pp. 12-14.

"Carta-Prólogo" a Francisco Soto y Calvo, El genio de la raza, Buenos Aires, s. $f$.

\section{JoHN E. ENGLEKIRK, Tulane University.}

(1) No he visto la primera edición publicada por Maucci en 1908; por eso no sé si en ella figura este "Prólogo" que fechó Unamuno en Salamanca en marzo del mismo año, el cual si figura en la sacada el mismo año por P. Ortega. 
